\title{
"APENAS PREENCHER PAPEL": REFLEXÕES SOBRE REGISTROS POLICIAIS DE DESAPARECIMENTO DE PESSOA E OUTROS DOCUMENTOS*
}

\author{
Letícia Carvalho de Mesquita Ferreira
}

Em 9 de março de 2009, a enfermeira Clara esteve em uma delegacia de polícia (DP) do Rio de Janeiro para relatar que seu sobrinho Domingos, 36 anos, solteiro, desempregado, saiu de casa na tarde de 15 de fevereiro daquele ano e nunca mais retornou, nem deu notícias. Assim que chegou à DP, entregou ao policial que a atendeu uma foto de seu sobrinho. O retrato foi anexado a um registro de ocorrência produzido pelo mesmo policial, dando origem ao que seria mais um caso de desaparecimento de pessoa ocorrido na cidade.

Mais de três meses depois, Clara compareceu ao Setor de Descoberta de Paradeiros (SDP) da Delegacia de Homicídios do Rio de Janeiro Centro/Capital, para onde o caso havia sido encaminhado. O SDP é um setor da Polícia Civil do Rio de Janeiro especializado em desaparecimentos de pessoa, e recebe diariamente casos registrados, mas não solucionados, em diversas DPs. Chegando ao Setor, Clara informou que o paradeiro de Domingos já lhe era conhecido há algum tempo, e disse estar ali para oficializar o fato. Em 27 de março, a enfermeira recebeu telefonema de uma comadre informando que Domingos estava internado em um centro psiquiátrico, e pôde enfim ir ao seu encontro.

Ao relatar o fato no SDP, Clara esclareceu que seu sobrinho desaparecera quando se encontrava sem destino certo, por ter sido demitido da universidade em que trabalhara por cerca de dez anos. Antes de deixar o Setor, a enfermeira assinou alguns papéis diante dos policiais ali presentes e, por fim, pediu que lhe devolvessem a fotografia de Domingos anexada ao caso, "por ser pertencente a um álbum de família" (SDP 018/08). ${ }^{1}$

\section{Introdução}

Domingos protagoniza um dos milhares de casos de desaparecimento de pessoa registrados anualmente em DPs brasileiras. Idosos acometidos por 
perdas temporárias ou definitivas de memória, adolescentes que fogem de casa e vítimas fatais de acidentes ou crimes cujos cadáveres não são identificados compõem, juntamente com Domingos, o múltiplo universo de sujeitos designados por policiais, gestores de políticas públicas, militantes de movimentos sociais e cientistas sociais como desaparecidos. A despeito de sua heterogeneidade, as experiências por eles vividas são encaradas por todos esses agentes como manifestações particulares de um só fenômeno: o desaparecimento de pessoas, também chamado de desaparecimento civil. ${ }^{2}$

No cotidiano das DPs, o desaparecimento de pessoa é um tipo de ocorrência classificado como fato atípico, já que não corresponde a qualquer tipo penal previsto em lei. Não constitui crime, não prescreve em prazos determinados e não pode gerar inquérito policial, embora seja, como outras ocorrências não criminais, objeto de registro, investigação e arquivamento em repartições policiais. Cada desaparecimento comunicado em uma DP dá origem a documentos que se acumulam ao longo do tempo, desde o primeiro registro do caso, normalmente um registro de ocorrência, até o relatório final, que determina seu arquivamento. A esses conjuntos de papéis, em sua maioria, produzidos por policiais, são ainda anexados suportes materiais de informação deixados nas delegacias por familiares e conhecidos dos desaparecidos, como, por exemplo, a fotografia de Domingos.

O presente artigo analisa registros documentais de casos de desaparecimento de pessoa produzidos e reunidos em DPs do Rio de Janeiro entre 2005 e 2009. Os papéis analisados encontram-se atualmente arquivados no SDP, setor da Polícia Civil do Rio de Janeiro a que Clara compareceu em março de 2009 e de onde retirou o retrato de seu sobrinho. Entre março de 2008 e dezembro de 2009, realizei trabalho de campo no SDP, tendo acompanhado a rotina dos cinco policiais que então compunham seu quadro ativo, os atendimentos ali prestados e as trajetórias de produção, circulação e arquivamento de documentos que anima o Setor. Motivada pela pesquisa de campo e pelas concepções dos policiais do SDP sobre o trabalho que realizam diariamente, no escopo deste texto busco explicitar os efeitos das trajetórias documentais constitutivas de desaparecimentos de pessoa sobre os enredos e os desfechos dos próprios casos.

A hipótese sustentada é de que a produção, a circulação e o arquivamento de documentos relativos a desaparecimentos têm dois efeitos principais: primeiro, propiciam espaços de tomada de posição para policiais que os registram, colocam em movimento e/ou guardam; e, segundo, promovem a delegação das responsabilidades de gestão dos casos às famílias dos desaparecidos. Se parentes, familiares e conhecidos de desaparecidos vão a delegacias de polícia em busca de investigação, gestão e/ou solução de 
desaparecimentos, como fez a enfermeira Clara, os encontros que travam com policiais engendram a delegação dessas tarefas de volta às unidades domésticas e círculos de relações em que tanto eles quanto os desaparecidos estariam inscritos. Essa delegação ganha sentido no marco mais amplo das posições de policiais diante do desaparecimento de pessoas, tomadas nos próprios documentos que dão materialidade aos casos. Tais papéis, portanto, não apenas acompanham formalmente esses dois processos, mas, ao contrário, são parte constitutiva e fundamental deles.

Além desta introdução, o artigo tem três partes, todas organizadas em torno de casos de desaparecimento. Na primeira parte, apresento o SDP, explicitando suas atribuições e as concepções dos policiais que lá atuam sobre o trabalho que realizam no cotidiano. Afirmo que documentos funcionam ali como espaços de tomada de posição por parte desses policiais. Na segunda parte, trato da importância atribuída aos documentos por sujeitos envolvidos em desaparecimentos, e das propriedades desses papéis no contexto dos Estados modernos. Sustento que documentos têm uma força social que, por um lado, escapa aos poderes de Estado e, por outro, funcionam como meio de ação de agentes de Estado. Partindo daí, argumento que policiais delegam a gestão de casos de desaparecimento às famílias de desaparecidos, e que os documentos desempenham papel central nesse processo de delegação. Na terceira parte, por fim, teço breves considerações conclusivas.

Para tanto, encaro os papéis específicos analisados ao longo do artigo, todos atualmente arquivados em gavetas, armários e fichários do SDP, como parte do universo mais amplo dos documentos oficiais, que ocupam lugar central nos regimes de autoridade, autenticação e produção de verdades vigentes nos Estados modernos. Documentos cumprem papel fundamental nas cadeias de atos, autoridades e autorizações que estruturam o campo burocrático (Bourdieu 1996) e, nesse sentido, são peças-chave da produção tanto de categorias e procedimentos a partir dos quais agentes, repartições e setores da administração pública estatal intervêm no mundo social, quanto da própria necessidade de intervenção. É desta maneira que a criação e a manutenção de arquivos podem ser vistas como emblemas máximos da burocracia moderna (Riles 2006:5).

Conforme argumenta Souza Lima (2002), em categorias jurídico-normativas, políticas públicas e procedimentos burocráticos, dentre os quais podemos destacar a própria criação e a manutenção de arquivos, há mais que aplicação de regras e normas predeterminadas a realidades supostamente dadas ao conhecimento. Categorias, políticas e procedimentos conectam-se aos mundos sociais que buscam circunscrever (e, muitas vezes, transformar) 
por meio de processos mais complexos e intrincados do que fazem supor os ideais de objetividade, formalismo e impessoalidade associados à burocracia (Weber 1963). Partindo dessa premissa, neste texto jogo luz especificamente sobre os processos implicados na produção, na circulação e no arquivamento de registros documentais de casos de desaparecimento de pessoa.

Desde a perspectiva analítica adotada aqui, documentos podem ser encarados como artefatos que exercem mais do que a função meramente referencial de registrar ou representar graficamente algo que existiria no mundo à sua revelia. A produção, o porte, a circulação e o arquivamento de documentos têm desdobramentos no mundo social, não só por seu efeito de verdade e por funcionarem, em certos contextos, como critérios de respeitabilidade, elegibilidade e acesso a benefícios e direitos (Santos 1979; Peirano 1986, 2006a, 2006b, 2009), mas também por produzirem e rearranjarem relações, além de serem capazes de transportar, conter ou incitar afetos de diversas ordens. Funcionam, em suma, não como artefatos estéreis e autocontidos, e sim como objetos materiais do direito, da administração e da governança capazes de produzir diferentes efeitos e engendrar múltiplos afetos e relações (Navaro-Yashin 2007:95). Cabe, portanto, investigar os efeitos provocados por registros documentais produzidos, manipulados e arquivados em contextos particulares. ${ }^{3}$

\section{Um trabalho policial que apenas informa}

\section{Antônio}

Maria e Antônio, policial civil aposentado, são casados no papel há mais de 30 anos, embora há quase 20 estejam separados. Maria tem, inclusive, um novo companheiro, de nome Jeferson. Desde 2007, por questões financeiras, Maria, Antônio e Jeferson vivem na mesma casa. Certa manhã de março de 2008, os três deixaram a residência juntos, mas com destinos diferentes, combinando de se encontrar em casa no final da tarde. Maria e Jeferson retornaram no horário marcado; Antônio, não. Estranhando sua ausência prolongada, Maria procurou por ele nas ruas do bairro em que moram, telefonou para alguns de seus parentes e esteve na agência bancária a que ele teria ido pela manhã, mas não o encontrou. Por fim, decidiu procurar a polícia.

Essa decisão levou Maria a três repartições: a 29a DP, a $6^{\mathrm{a}} \mathrm{DP}$ e o Setor de Descoberta de Paradeiros (SDP) da então Delegacia de Homicídios (DH) do Rio de Janeiro Centro/Capital. ${ }^{4} \mathrm{Na} 29^{\mathrm{a}} \mathrm{DP}$, foi informada de que o caso 
só poderia ser registrado como desaparecimento de pessoa 48 horas depois de Antônio ter saído de casa. Frustrada com a informação, seguiu para a $6^{\mathrm{a}} \mathrm{DP}$, onde tampouco logrou obter um registro do caso. Sob a justificativa de que se tratava de ocorrência envolvendo um policial aposentado, o que distinguiria o desaparecimento de Antônio de outros casos ali registrados, um agente daquela delegacia orientou Maria a comparecer pessoalmente à $\mathrm{DH}$ e procurar pelos serviços do SDP.

O SDP é um setor da Delegacia de Homicídios especializado em casos de desaparecimento de pessoa. Conforme define o único instrumento legal que regula sua atuação, casos de desaparecimento registrados nas delegacias compreendidas entre a $1^{\mathrm{a}}$ e a $44^{\mathrm{a}} \mathrm{DP}$ do Rio de Janeiro que não sejam solucionados nessas repartições devem ser encaminhados ao Setor. As DPs têm o prazo regulamentar de 15 dias para investigar e solucionar os casos. Caso não obtenham sucesso, a investigação passa a ser encargo da equipe de cinco policiais civis que compõem o quadro ativo do SDP (Rio de Janeiro 1991). À medida que chegam ao Setor, os casos são distribuídos entre os policiais, e cada desaparecimento fica sob responsabilidade de um agente. De acordo com essas normas, portanto, o Setor só deve receber casos por remessas documentais realizadas entre repartições policiais, não tendo por atribuição registrá-los a partir de solicitações diretas de comunicantes — isto é, de conhecidos, parentes e familiares de pessoas consideradas desaparecidas que vão a delegacias e os relatam. Casos, nesse universo, são entidades materiais irredutíveis (Hull 2012a:116), que consistem em conjuntos de papéis relativos a desaparecimentos produzidos e/ou reunidos por policiais. ${ }^{5}$

Ao ser recebido no SDP, a primeira providência tomada diante de cada caso costuma ser um telefonema para o respectivo comunicante. Caso as informações obtidas nesse telefonema sejam consideradas definitivas, apresentando o desenlace do desaparecimento, os papéis são arquivados logo em seguida. Caso contrário, outras providências, intituladas de modo genérico como diligências, são tomadas. As diligências mais regulares são, em primeiro lugar, o envio de ofícios e outros documentos do Setor para instituições e órgãos públicos, policiais e não policiais, solicitando informações que possam elucidar o caso. Em segundo lugar, consultas por computador a sistemas de informação, como a Rede Infoseg (Rede de Integração Nacional de Informações de Segurança Pública, Justiça e Fiscalização) ${ }^{6}$ e a base de dados do Detran-RJ - órgão que, entre outros, emite documentos de identificação civil no estado do Rio de Janeiro.

O rol de instituições consultadas via ofício e sistemas de informação varia a cada desaparecimento, de acordo com os endereços registrados no 
caso - endereços do comunicante, do desaparecido e daquele que policiais chamam de local do fato, referindo-se ao lugar onde o desaparecido teria sido visto pela última vez. As instituições mais comumente consultadas são hospitais públicos, o Instituto Médico-Legal, o Instituto de Identificação Félix Pacheco, a Santa Casa de Misericórdia (exclusivamente os arquivos que registram nomes de pessoas sepultadas nos 13 cemitérios por ela administrados no Rio de Janeiro), a Fundação Leão XIII, que coordena abrigos e projetos assistenciais e, por fim, a Secretaria de Estado de Administração Penitenciária.

Esse leque de instituições indica as hipóteses regularmente aventadas por policiais diante dos casos: desaparecimentos redundariam, de seu ponto de vista, em internações em hospitais, mortes que restaram a cargo de órgãos públicos, atendimentos em serviços de assistência social e/ou detenções. Por outro lado, indica também que as investigações por eles realizadas dirigem-se quase exclusivamente a órgãos de administração pública que funcionam como pontos de verificação (checkpoints) e registro de identidades pessoais. Pontos de verificação, conforme mostra Jeganathan (2004), são empreendimentos e entidades oficiais que buscam, através da checagem e do registro de identidades pessoais, mapear, localizar e antecipar fluxos, deslocamentos e processos que potencialmente ameaçam a ordem social no contexto de um Estado.

Se alguma dessas diligências solucionar o desaparecimento ou se o comunicante informar à polícia que o desaparecido foi encontrado, os papéis produzidos e reunidos em delegacias são arquivados no SDP como caso solucionado. Do contrário, o caso segue por períodos variados de tempo em andamento, e só é arquivado quando o policial dele encarregado julga não ser mais procedente nem aguardar novas informações, nem empreender novas diligências. Esses são considerados casos suspensos. O arquivamento de casos solucionados e suspensos depende da autorização de um delegado da Delegacia de Homicídios, solicitada mediante relatório produzido pelo policial do SDP que se encarrega do caso.

Esses processos, porém, só são levados a cabo se as DPs, que têm a prerrogativa de registrar os casos, não lograrem solucioná-los. Não foi isso o que ocorreu no desaparecimento de Antônio, porém. Contrariando a norma, o policial do SDP que recebeu Maria achou por bem atendê-la e produzir um registro de ocorrência intitulado desaparecimento de pessoa em nome de Antônio. Justificou a exceção no corpo do documento, afirmando ter produzido o registro para suavizar o sofrimento de Maria — sofrimento não de ter um familiar desaparecido, mas de percorrer diferentes delegacias e não receber atendimento adequado. 
As afirmações feitas pelo policial no registro apontam para a potencial eficácia de enunciados sobre o sofrimento do outro (Boltanski 1993) especificamente no tocante a casos de desaparecimento. Destacam, nesse sentido, o périplo imposto à Maria pela recusa do registro imediato na primeira DP em que ela esteve e, em seguida, pela sugestão de que o caso seria tratado com distinção e registrado diretamente no SDP pelo fato de Antônio ser policial aposentado. Com efeito, foi isso o que ocorreu: o caso foi excepcionalmente registrado no Setor. Não obstante, as justificativas para que isso fosse feito acionaram não a identidade profissional do desaparecido, e sim o sofrimento da comunicante, na condição de familiar de desaparecido, em face da Polícia Civil:

Independentemente da peregrinação sofrida por muitos familiares de pessoas desaparecidas, fica cada vez mais notória a falta de informação dentro do próprio organismo da Polícia Civil, seja no que diz respeito ao registro do desaparecimento, seja a área de sua atribuição. No ensejo de amenizar o périplo da comunicante e melhor definir uma solução para que se dê início às buscas do paradeiro do cidadão desaparecido, foram tomadas a termo as declarações ora apresentadas para conhecimento e providências cabíveis (SDP/DH 061/08).

Como mencionei anteriormente, o desaparecimento de pessoas é classificado em repartições policiais como fato atípico, categoria que engloba ocorrências às quais não corresponde qualquer tipo penal previsto na lei brasileira, mas registradas cotidianamente em delegacias. ${ }^{7}$ Por não constituir crime, não gera inquéritos policiais. ${ }^{8} \mathrm{O}$ conjunto de documentos relativo a cada desaparecimento, diferente de inquéritos, tem permanentemente o estatuto de Verificação Preliminar de Informação (VPI), também chamada Verificação de Procedência de Informação, enquanto permanece na DP onde foi feita a comunicação do caso. ${ }^{9}$ O termo comunicação, bem como comunicante, é utilizado diante de desaparecimentos precisamente porque, não se tratando de crime, policiais consideram inadequado falar (e escrever) queixa, denúncia e/ou denunciante. Pessoas consideradas desaparecidas, nesse mesmo sentido, não são denominadas vítimas, e sim desaparecidos, o que muitas vezes leva policiais a rasurarem o termo vítima impresso em alguns formulários-padrão preenchidos em delegacias.

No SDP, toda VPI de desaparecimento ganha o estatuto de Sindicância. Na percepção dos policiais do Setor, Sindicâncias são só procedimentos administrativos, pouco efetivos e pouco relevantes se comparados a inquéritos policiais. ${ }^{10}$ Essa relativa irrelevância e a pouca efetividade dos papéis que compõem Sindicâncias integram uma percepção mais ampla vigente entre 
policiais: a ideia de que tanto o desaparecimento é ocorrência desimportante diante daquelas a que correspondem tipos penais, quanto os agentes dedicados exclusivamente a casos de desaparecimento, como são os policiais do SDP, são desvalorizados diante de colegas que lidam com ocorrências criminais.

Esse entendimento estaria entre as causas, por um lado, de um amplo desconhecimento sobre o desaparecimento de pessoa entre policiais, denunciado no papel no caso de Antônio; por outro, de frustrações entre aqueles que lidam regularmente com esse tipo de ocorrência, como os agentes do SDP. Parte mais evidente desse desconhecimento apareceria no que os policiais chamam de mito das 48 horas, também presente no caso de Antônio: o entendimento bastante difundido em delegacias, embora desprovido de respaldo legal, de que casos de desaparecimento só podem ser registrados dois dias depois de constatados. Se a imposição da espera é aspecto-chave de estruturas burocráticas (Hoag 2011:86), no tocante à lida de policiais com desaparecimentos, ela ganha contornos precisos (48 horas) e é um modo regular de operação. Esse modo de operação é não só motivo de frustração entre policiais do SDP, como também justifica exceções adotadas por esses agentes, como indica o caso do policial aposentado, registrado diretamente no Setor.

Um segundo motivo de frustração no SDP é a própria classificação do desaparecimento como fato atípico. Diante da falta de um tipo penal que estabeleça o que é desaparecimento de pessoa, policiais afirmam sentir-se desprovidos de diretrizes claras e cursos de ação bem definidos a serem seguidos diante dos casos. Essa falta explicaria, na perspectiva dos policiais, o que o trabalho de campo no Setor tornou mais evidente ao meu olhar: é na lida diária com os documentos que registram e arquivam diariamente que esses agentes definem e redefinem o que é (e o que não é) desaparecimento de pessoa. Policiais que lidam com este tipo de ocorrência estabelecem as fronteiras empíricas de sua atuação não segundo marcos predeterminados por leis e regulamentos prescritos, como seria esperado em burocracias (Hoag 2011:83), mas a partir de classificações e tomadas de posição pouco formais, mas não pouco efetivas, produzidas e reproduzidas em sua própria rotina de produção, circulação e arquivamento de papéis.

A classificação mais fundamental que orienta essa constante definição do que seja desaparecimento conforma um par de opostos que aparece abundantemente em conversas, documentos e atendimentos efetuados no SDP: problemas de família e problemas de polícia. Esse par parece organizar satisfatoriamente, do ponto de vista dos policiais, a heterogeneidade de dramas registrados em delegacias sob o título desaparecimento de pessoa, 
que abarca desde fugas do lar empreendidas por adolescentes, casos de idosos que perdem temporária ou definitivamente os sentidos, adultos que optam por deixar suas casas, empregos e rotinas, e vítimas fatais de crimes cujos cadáveres não são encontrados, e até andarilhos, pedintes e sujeitos que vivem na mendicância, entre tantos outros. Ao acionar esse par de categorias, policiais logram não apenas definir o que é desaparecimento, estabelecendo assim os limites de sua atuação, mas também explicitar seu entendimento quanto à relevância e à efetividade de seu trabalho diante dos múltiplos casos assim intitulados.

Da perspectiva de policiais, desaparecimentos são problemas de família, em oposição ao que seriam problemas de polícia. Não configuram episódios de violência urbana ou criminalidade, o que estaria evidenciado na ausência de um tipo penal a eles correspondente, e por isso destoam do que seria claramente atribuição da polícia. ${ }^{11}$ Recorrendo a essa dicotomia entre tipos supostamente excludentes de problemas, policiais contrapõemse a possíveis definições mais abrangentes do que pode ser considerado trabalho policial. ${ }^{12}$ Para tanto, afirmam, registram e enfatizam de diferentes maneiras, em distintas ocasióes, que casos de desaparecimento consistem em fatos acarretados por conflitos não criminais cujas causas, desdobramentos e soluções cabem exclusivamente a famílias. ${ }^{13}$

Entre muitos outros, o caso de Antônio endossaria esse entendimento, tendo a propósito sido citado como exemplar do que seja desaparecimento pelo policial do SDP com quem travei os primeiros contatos no trabalho de campo. O desaparecimento do policial aposentado teve como desfecho seu encontro pela própria Maria, que decidiu procurá-lo em uma cidade de Minas Gerais para a qual costumavam viajar de férias no passado. Maria foi sozinha para a tal cidade em busca do desaparecido, onde o encontrou hospedado "em um hotel, alegando que estava ali para descansar" (SPD/DH 061/08). No dia seguinte ao encontro, Maria esteve pessoalmente no SDP e informou que o caso estava solucionado. Levou consigo a carteira funcional de Antônio, que comprovaria, de seu ponto de vista, que o policial aposentado não era mais um desaparecido.

O porte do documento por Maria foi ao encontro de uma das práticas empregadas correntemente por agentes do SDP diante de desaparecimentos. Também do ponto de vista dos policiais, documentos de identificação civil e/ou funcional têm a capacidade de comprovar que um sujeito não é mais desaparecido, como supôs Maria diante do caso de Antônio. Para policiais, porém, esses documentos funcionam como evidências e como justificativas suficientes para o encerramento de investigações e arquivamento de casos. Não são raros os casos arquivados no Setor após a constatação, por 
meio de consultas a sistemas de informação, da emissão de documento de identificação civil em nome do desaparecido em data posterior à de seu desaparecimento. No SDP, ao menos em certos casos, obter documento de identificação significa não poder ser considerado desaparecido, confirmando no limite que determinado papel, em determinados contextos, "legaliza e oficializa o cidadão e o torna visível, passível de controle e legítimo para o Estado; o documento faz o cidadão em termos performativos e obrigatórios" (Peirano 2006a:27).

Mais adiante retomo esta questão e apresento outros matizes e significados atribuídos a documentos no SDP. Antes, porém, retomemos as concepções em torno do desaparecimento de pessoas vigentes entre os policiais do Setor.

\section{Daniela}

Tanto quanto conversas mantidas no SDP, e tanto quanto casos como o de Antônio, o desaparecimento de Daniela configura uma de muitas ocasiões em que policiais do Setor fazem, refazem e enfatizam afirmações sobre desaparecimentos serem problemas de família. Os registros do caso, nesse sentido, não apenas se referem ao desaparecimento de Daniela e às diligências empreendidas por policiais diante dele, mas sobretudo permitem a esses agentes posicionar-se quanto ao que é desaparecimento e quanto às suas responsabilidades diante dessa ocorrência. Daniela, uma secretária de 22 anos, deixou as duas filhas pequenas sob os cuidados da avó, saiu de casa para trabalhar e não retornou mais. O caso foi arquivado no SDP um ano e três meses após ter sido registrado em uma DP sob a seguinte justificativa:

[...] deve ter ocorrido algum problema familiar que fez com que DANIELA saísse de casa, já que segundo a comunicante a sua filha ligou no carnaval deste ano dizendo que iria aparecer, mas que infelizmente até a presente data não foi visitar a mãe. Assim sendo, passo à apreciação e deliberação de V. S., uma vez que a presente sindicância encontra-se solucionada neste serviço de descoberta de paradeiros. É o que me cumpre informar (SDP/DH 030/07).

Este registro foi firmado no relatório final do caso de Daniela, em que o policial do SDP solicitou autorização para arquivar os papéis a ele referentes. A autorização foi requisitada não porque o paradeiro de Daniela tivesse sido descoberto, nem porque ela tivesse obtido documento de identificação civil 
em data posterior ao desaparecimento, mas porque não caberia à polícia lidar com problemas de família. Inscrevendo, portanto, o desaparecimento da secretária no cotidiano de suas relações familiares, policiais retiraram-lhe a excepcionalidade e, assim, tornaram não só desnecessária, como também improcedente a atuação policial diante do caso. Esse curso de ação assemelha-se ao que Enne, Carrara e Vianna (2002) revelam sobre a administração judicial de casos de violência contra a mulher no Rio de Janeiro.

Da perspectiva de policiais, diante deste tipo de problema, a polícia não tem nem obrigações, nem meios adequados de atuação. Tramas delicadas, que geram sofrimento e requerem habilidades e procedimentos distintos do que demandam os problemas de polícia, casos de desaparecimento "não são serviço nosso, mas a gente acaba fazendo", como me disse certa vez a policial que chefiou o SDP durante meu trabalho de campo. Diante desses casos, policiais consideram que tudo o que fazem e podem fazer resume-se a apenas preencher papel, e sustentam que a busca por desaparecidos e a efetiva investigação dos casos não devem ser realizadas em delegacias, às quais restaria apenas produzir documentos - documentos estes, vale lembrar, que gozam do estatuto de só procedimentos administrativos. Em suma, mais que um idioma de autoexoneração como os frequentemente acionados em repartições públicas (Herzfeld 1992:135-156), "acabar fazendo" significa, no SDP e em outras repartições policiais que lidam com desaparecimentos, preencher e arquivar formulários, relatórios e outros documentos diante de dramas que atravessaram, equivocadamente, uma fronteira tão invisível quanto operante que separaria problemas de família de problemas de polícia.

Em meio à heterogeneidade de casos registrados como desaparecimento, há aqueles, porém, em que pululam relatos sobre possíveis crimes, como homicídio, sequestro, destruição de cadáver e desaparecimento forçado de pessoa, entre outros. ${ }^{14}$ Tais casos estariam inscritos no universo dos problemas de polícia, dariam sentido às categorias violência urbana e criminalidade e justificariam, a princípio, a instauração de inquéritos policiais. Seriam, enfim, capazes de conferir importância ao desaparecimento, ao trabalho dispensado a esse tipo de ocorrência e, consequentemente, aos policiais que o executam. Como veremos no caso de Elói, no entanto, não é isso o que acontece.

\section{Elói}

Nascido em Saquarema, o jovem Elói, de 20 anos, morava sozinho em Vila Isabel, em imóvel pertencente à sua mãe. Numa noite de agosto de 
2005, recebeu três amigos em casa. Os quatro partiriam na manhã seguinte para Saquarema, onde passariam alguns dias na casa dos pais de Elói. Por volta de 11 horas da noite, porém, Elói saiu para comprar drogas no Morro São João e não mais retornou, nem deu notícias.

Gilson, pai do jovem, veio ao Rio de Janeiro procurar pelo filho, e esteve seguidas vezes no IML e em hospitais públicos da cidade. Sem sucesso nessas buscas e portando consigo uma fotografia do filho, foi enfim a uma DP. Relatou então, sem citar fontes, que seu filho teria se desentendido com traficantes e sido morto em seguida, mas que seu corpo não havia sido encontrado. Gilson recebera duas informações contraditórias sobre o destino do cadáver: ele teria sido abandonado dentro de um veículo incendiado em Madureira, mas poderia também ter sido desovado na divisa entre os Morros São João e Macacos. Policiais militares de dois batalhões teriam feito buscas pelo corpo nos dois morros, sem sucesso.

O policial que recebeu Gilson na DP registrou o caso e, a seguir, solicitou informações sobre Elói a instituições que poderiam tê-lo internado, preso ou mesmo sepultado. Nenhuma das instituições forneceu qualquer informação sobre o jovem. Quatro meses depois, o caso foi encaminhado ao SDP, onde a primeira diligência empreendida foi a convocação de Gilson.

No SDP, Gilson relatou fatos de que tomara conhecimento logo após o desaparecimento de Elói e que fariam parte da trajetória do jovem pelo "mundo da ilegalidade" (SDP/DH 394/05), como o pai o chamou. Elói faria parte de um esquema de roubo de mangueiras de incêndio de prédios residenciais, além de ser comprador assíduo de drogas em uma boca de fumo rival àquela a que teria se dirigido na noite em que foi morto. Sobre a morte do jovem, disse que o assassinato teria sido confirmado "por moradores da comunidade, o que fez o comunicante acreditar que realmente seu filho tenha sido morto por traficantes daquela 'boca de fumo'" (SDP/DH 394/05).

Diante das novas declarações de Gilson e dos documentos produzidos sobre o caso na DP, o policial do SDP empreendeu mais uma única e definitiva diligência: produziu um relatório sobre o caso solicitando autorização para arquivá-lo. Embora repleto de suspeitas de crime, a narrativa comovida, comovente e, ao mesmo tempo, resignada e autoexoneradora do policial configura um espaço de tomada de posição e classificação de desaparecimentos como problemas de família, diante dos quais cabe à polícia, fatalmente, apenas preencher papel. Os personagens em destaque na narrativa são pai e filho, e não traficantes, e os fatos ressaltados são aqueles que indicariam desvios na vida de um filho ingrato, e não um assassinato. Amortecidos e inscritos no cotidiano da vida desviante de Elói, os acontecimentos são apresentados como memórias de "um álbum de família", para 
relembrarmos registros do caso de Domingos, e não problemas de polícia. Consequentemente, o trabalho policial aparece na narrativa como conjunto de só procedimentos administrativos que nada mais fazem, nem poderiam fazer, além de produzir documentos:

Desocupado e morando sozinho, o jovem Elói se aproveitava do sustento que o pai proporcionava para alimentar seu vício; acreditava o pai que o mantendo financeiramente o teria mais perto, mesmo dando-lhe espaço físico e geográfico, pois mudou-se com a mulher para Saquarema para lhe proporcionar maior liberdade, na melhor das intenções. No entanto, a partir do desaparecimento, encontrou um rastro de desordem e apenas a notícia de que o filho saíra para comprar drogas em um morro, enquanto alguns amigos esperavam em casa, porém, não mais retornou. A partir daí surgiram inúmeros comentários e detalhes mórbidos do que teria sido sua execução por parte dos traficantes, não se sabendo a razão ou mesmo se são verdadeiras ou falsas. Resta o registro de desaparecimento, antecipação de um óbito imaginário; resta um trabalho policial que pouco conforma, apenas informa que não há registros em nome daquele desaparecido. Infelizmente. Nada encontrado. Nenhum registro. Nenhuma esperança de vida. Assim exposto, considerando o tempo decorrido desde sua instauração; considerando a carência de indícios ou fatos; considerando as respostas negativas às pesquisas realizadas, solicito a Vossa Senhoria a SUSPENSÃO da Sindicância, até segunda ordem, salvo melhor juízo. É o que me cumpre informar (SDP/DH 394/05).

Registros ao mesmo tempo emocionados e resignados como os que constituem o caso de Elói, assim como falas sobre "acabar fazendo" e expressões como apenas preencher papel e só procedimentos administrativos, apontam para três dimensões da administração de casos de desaparecimento de pessoa em repartições policiais: 1. indicam que policiais não percebem sua atuação diante de casos de desaparecimento nem como algo pertinente, nem como algo efetivo, e enunciam isso nos próprios papéis que produzem, colocam em circulação e arquivam diariamente; 2 . evidenciam que esses agentes concebem os atos de preencher e arquivar documentos como a integralidade de seu trabalho (isso é tudo o que eles fazem) mas, ao mesmo tempo, como algo pouco ou nada importante (já que tudo o que eles fazem é apenas preencher papel, num trabalho policial que apenas informa); e 3. explicitam, na materialidade dos papéis, que para policiais esses afazeres de menor importância são inevitáveis e inexoráveis, carregando consigo ares de coisa do destino. Conforme sugere Herzfeld (1992:139), a ideia de destino, dentre os idiomas e símbolos acionados em repartições, encontros e 
práticas burocráticas, permite tanto a cidadãos quanto a burocratas lidarem com frustrações, humilhações e derrotas vividas durante e em função de suas interações sem perderem o autorrespeito.

Motivação principal deste artigo, essas dimensões da administração policial de casos de desaparecimento tornam imperativo atentar para os documentos que policiais manipulam diariamente. Não obstante, esse imperativo é ainda reforçado por inúmeras referências a outros papéis presentes em casos de desaparecimento.

\section{Pertencente a um álbum de família}

\section{Quincas, Belmiro e Elias}

As irmãs Neusa e Inácia moram juntas em uma casa na Tijuca e há algum tempo emprestam um barracão nos fundos do terreno para Quincas, um senhor que faz tratamento psiquiátrico no Instituto de Psiquiatria da UFRJ (IPUB). Certa tarde, Neusa foi ao barracão convidar Quincas para almoçar, mas encontrou apenas um bilhete:

Dona Inácia e Dona Neusa, desculpem estar dizendo essas palavras, mas eu estou sem destino, sei que a minha vida vai ser um inferno saindo dessa casa, nunca encontrei duas pessoas que gostassem tanto de mim. Vocês sabem que eu não sou maluco, isso é coisa do destino, peço muitas desculpas por estar saindo dessa maneira, não sei para onde vou, mas peço, por favor, guardem todos os meus documentos para mim. Quincas. Pelo menos um bilhete eu deixei pra vocês (SDP/DH 004/07).

No dia seguinte, portando o bilhete, um cartão do IPUB e duas fotografias de Quincas, Inácia foi à $19^{\mathrm{a}} \mathrm{DP}$ e relatou o ocorrido a um inspetor. O policial produziu então um registro de ocorrência em nome de Quincas que, dois meses depois, foi encaminhado ao SDP junto do bilhete, do cartão do IPUB e das fotografias. Assim que recebeu os documentos, um policial do Setor telefonou para a residência de Inácia para se atualizar sobre o caso. Soube então que Quincas havia retornado.

Enredo semelhante foi protagonizado pela professora Sílvia e por seu marido, o guarda municipal Belmiro. Certa manhã de março de 2008, Sílvia esteve na $37^{\mathrm{a}} \mathrm{DP}$, na Ilha do Governador, e seus relatos deram origem a um caso de desaparecimento em que ela consta como comunicante e Belmiro, como desaparecido. Diz o registro: 
Segundo a comunicante, seu marido, guarda municipal e dependente químico em tratamento médico, saiu de casa sem dar notícias. Que ultimamente ele andava em crise e teria sido visto pela última vez reclamando muito da vida e dizendo que estava de saco cheio e que iria "descacetar" (sumir, desaparecer). Segundo a comunicante, ele andava muito agressivo, parou de fazer a barba e o cabelo e de se cuidar, mas antes de sair levou sua carteira de guarda, cartões de benefício do INSS [Instituto Nacional do Seguro Social], cartão bancário e um pequeno álbum de fotos. Que veio registrar o fato a pedido da perícia da guarda municipal, já que ele teria que se apresentar para exame periódico (SDP/DH 187/08).

Nos três meses seguintes, três mandados foram remetidos a Sílvia, intimando-a a comparecer à DP, mas nenhum foi atendido. Em julho de 2008, o caso foi enfim encaminhado ao SDP, onde o único registro produzido foi um relatório em que o policial dele encarregado solicitava seu arquivamento. No documento, o agente afirma ter telefonado para Sílvia e recebido a informação de que Belmiro retornara dias antes.

O zelo dispensado a documentos por Quincas e Belmiro aponta para a máxima importância e as múltiplas capacidades atribuídas a esses e a outros papéis que certificam e asseguram identidades, relações e direitos não só em repartições policiais, mas no contexto geral dos Estados. Artefatos gráficos, como cartões de benefício do INSS, carteira da guarda municipal e, conforme mostra Peirano (1986, 2006a, 2006b), carteiras de identificação civil, carregam consigo o simbolismo da estabilidade, e são objetos de valor permanente em função do status igualmente permanente atribuído aos vínculos que estabelecem, manifestam e/ou garantem entre seus portadores e o Estado. "Documentos integram a parafernália basilar dos Estados modernos e de sistemas legais: eles são sua cultura material" (Navaro-Yashin 2007:84, tradução livre) e, nesse sentido, são mais que meros rastros materiais de poderes e fazeres de Estado ou, como afirma DaMatta (2002), "a mão visível do Estado".

Documentos são artefatos que, como toda prática burocrática, afirmam a teleologia básica do Estado e sua autoridade quase demiúrgica sobre atos oficiais de consagração (Herzfeld 1992; Bourdieu 1996). Sua produção, sua circulação e seu arquivamento reproduzem tanto o Estado-ideia quanto o Estado-sistema que, para fins de análise, podemos distinguir como partes constitutivas do Estado moderno (Abrams 1988). Se, por um lado são materializações de vínculos entendidos como permanentes entre sujeitos e Estados, performativamente fazendo desses sujeitos cidadãos, por outro, documentos são também condições para que procedimentos, trâmites e demandas sejam desembaraçados em diferentes aparatos de administração pública. O registro do desaparecimento de Belmiro, por exemplo, foi 
efetuado não porque Sílvia desejava que a polícia investigasse o caso, mas para cessar responsabilidades advindas da ausência do guarda municipal na perícia médica a que ele deveria comparecer. O documento policial que certificasse o desaparecimento do guarda teria, se aceito por servidores da guarda municipal, capacidade de interromper ou evitar processos administrativos e/ou judiciais que causassem transtornos e penalidades a Belmiro. Seguindo essa cadeia, tal documento teria também capacidade de evitar problemas à própria Sílvia, casada com o guarda no papel.

Não obstante, e indissociavelmente, esses papéis têm ainda uma segunda capacidade: permitem que os sujeitos a que se referem e que os possuem, portam e/ou colocam em circulação particularizem-se e inscrevamse de modo estável não só na realidade do mundo estatizado que habitam, mas também e indissociavelmente no curso de suas próprias vidas (Caplan \& Torpey 2001:6-7). Lembremos, nesse sentido, que Belmiro desapareceu levando consigo cartão da guarda municipal, carteirinha do INSS e um álbum de fotos; e, ainda, que Quincas se apresentou, no bilhete deixado à Neusa e Inácia, como alguém sem destino que, no entanto, preocupa-se em manter seguros seus documentos. Se "documentos têm uma vida simbólica dentro de um determinado Estado" (Peirano 2006a:35), eles não apenas fazem dos sujeitos (propriamente documentados) cidadãos daquele Estado, mas também "estabelecem o indivíduo como único e particular e produzem, no mundo moderno, um máximo de singularização e uma individualização idealmente absoluta" (Peirano 2006a:27).

Outro caso ilustrativo dessa dupla capacidade dos documentos é o de Elias, um vigia que vivia em uma quitinete vizinha à casa de Alice, uma de suas três irmãs. Depois de quase duas semanas sem notícias dele, Alice comunicou o desaparecimento do irmão em uma DP. O policial que a atendeu redigiu, no registro de ocorrência em nome de Elias, que Alice havia estado na quitinete do vigia, que "estava perfeita, com tudo arrumado, inclusive com todos os documentos de Elias dentro da casa" (SDP/DH 051/07). Investigando registros de entrada de cadáveres no IML, o policial descobriu que um homem com características físicas semelhantes às de Elias havia sofrido um atropelamento fatal dias antes e encontrava-se no Instituto aguardando identificação. Era Elias. Como fora atropelado sem portar consigo seus documentos, caso não fosse identificado por meio de suas impressões digitais, além de reconhecido e reclamado por um familiar, o vigia seria sepultado como indigente, em uma vala comum. ${ }^{15}$

O desaparecimento de Elias não apenas evidencia o simbolismo da estabilidade carregado pelos documentos e a dupla capacidade advinda daí (a de fazer dos sujeitos cidadãos, e a de permitir a inscrição desses sujeitos em suas 
próprias trajetórias de vida), como também anuncia efeitos engendrados pelo porte, a circulação e, consequentemente, a ausência de documentos - como, por exemplo, ser sepultado como indigente. Se o fato de obter determinados documentos retira do sujeito a condição de desaparecido, Elias deixa claro que não os possuir faz dele, em certas circunstâncias, um indigente. A necessidade de ter e de portar documentos, afinal, "tem seu lado inverso: o de remover, despossuir, negar e esvaziar o reconhecimento social do indivíduo que não possui o documento exigido em determinados contextos" (Peirano 2006a:27).

\section{Álvaro}

Casos de desaparecimento explicitam duas ordens de efeitos provocados pelos documentos em que estão registrados: 1. efeitos imprevistos, indicativos da força social desses papéis que, nas palavras de Peirano, "na sua tentativa dominante de racionalidade, o Estado não controla" (2006a:38); e 2. efeitos regulares, que sugerem que essa mesma força é muitas vezes parte constitutiva das práticas rotineiras de agentes do Estado. A exemplo do caso de Álvaro, narrado a seguir, alguns desaparecimentos tornam evidente que a produção e a circulação de papéis oficiais engendram processos improváveis e em certo sentido incontroláveis, e que sua força muitas vezes excede o espaço administrativo do Estado-sistema, tendo efeitos para além de paredes institucionais, pontos de verificação, delegacias de polícia e outras repartições públicas. Não obstante, outros casos, narrados mais adiante, indicam que por vezes essa força é fundamental para a consecução de processos e fazeres burocráticos previsíveis, controlados e até mesmo desejados por agentes de Estado como, por exemplo, policiais civis.

Servidor público municipal de 59 anos, Álvaro saiu de casa dizendo que iria "beber e dar uma volta" (SDP/DH 099/06), como fazia de hábito, mas não retornou. Uma semana depois, sua irmã, com quem dividia um apartamento, foi a uma DP comunicar o fato, levando consigo um retrato $3 \times 4$ dele. Três meses depois, o caso foi encaminhado para o SDP sem qualquer pista de onde Álvaro poderia estar, mas tendo entre seus registros aquela foto $3 \times 4$.

O SDP foi então procurado por uma também servidora da prefeitura do Rio de Janeiro, que solicitou da polícia não informações sobre Álvaro, mas que algum familiar dele fosse encontrado e comparecesse à prefeitura para oficializar o desaparecimento e "assinar os devidos documentos" (SDP/DH 099/06). Essa necessidade de documentação gerou buscas em sistemas de informação que permitiram que os policiais localizassem Valéria, filha de Álvaro, e a convocassem a comparecer ao SDP. 
Para surpresa dos policiais, Valéria foi ao SDP já na manhã seguinte à convocação para informar que até poderia ir à prefeitura oficializar o desaparecimento, mas que nada sabia sobre o caso, nem sobre Álvaro. A filha do desaparecido não via o pai desde bebê e naquela oportunidade, em função de sua ida ao Setor, pôde visualizar o rosto dele pela primeira vez, através da foto 3x4 incluída entre registros policiais. Diante da estupefação dos policiais, antes de deixar o SDP Valéria pediu a fotografia "para sua guarda pessoal" (SDP/DH 099/06).

O caso de Álvaro deixa claro que o acionamento da relação de filiação entre ele e Valéria, que não existia senão em registros burocráticos, foi um efeito direto desses registros mesmos e da necessidade de oficialização do desaparecimento na prefeitura. Pode ser visto, portanto, como um produto inesperado da força social movida pela produção e a circulação de documentos oficiais, cujos efeitos ultrapassam paredes institucionais. Ademais, o caso do servidor, que se encerra com o trânsito da foto 3x4 do maço de documentos que compõem aquele desaparecimento para a "guarda pessoal" de Valéria, evidencia que múltiplos afetos estabelecidos entre pessoas e documentos podem ser considerados facetas das artes de governar (Navaro-Yashin 2007:88), ainda que inauditas, dificilmente controláveis e surpreendentes.

Mas se casos como o de Álvaro revelam efeitos imprevistos da força social dos documentos, outros explicitam os efeitos mais regulares que esses papéis podem provocar. Práticas burocráticas, em especial as de registro e documentação, acionam processos fundamentais para o funcionamento do Estado-sistema, desde aqueles previstos em regulamentos, normativas e leis, até outros não regulamentados ou mesmo ilegais, embora desejáveis e previsíveis do ponto de vista de burocratas. A produção de uma agência coletiva e, portanto, a desindividualização de atos e responsabilidades descrita por Hull (2012a) é exemplo de um desses processos, bem como a reprodução de percepções englobantes e verticalizadas do Estado, como as etnografadas por Ferguson \& Gupta (2002). Ainda que muito do trabalho de burocratas aconteça em breves interações através de balcões, demandas, reclamações, recusas e processos muito variados, desde os mais formais e padronizados até os mais complexos, encontram seu caminho no papel e tornam-se, assim, bastante efetivos (Hull 2012a:113).

\section{Arlete, Cinira e Melissa}

Se, como argumentei anteriormente, policiais lidam com desaparecimentos a partir do par de opostos problemas de família e problemas de 
polícia, indexando os mais variados casos segundo a primeira categoria, agora, para encerrar o texto, busco demonstrar que esses agentes não apenas classificam os casos como problemas de família, como também atribuem as responsabilidades de gestão de cada um deles às famílias dos desaparecidos. Uma das forças motrizes desse processo, como indicam os casos de Arlete, Melissa e Cinira, é precisamente a capacidade dos documentos de provocarem efeitos que ultrapassam paredes institucionais e transpõem a linha divisória, produzida pelos próprios policiais, que separaria os universos problemas de polícia e problemas de família.

Nestes três casos, todos envolvendo adolescentes que deixaram suas casas voluntariamente e retornaram depois de diferentes intervalos de tempo, as famílias das desaparecidas aparecem como unidades domésticas que devem se autogerir e, portanto, administrar seus problemas, como por exemplo casos de desaparecimento. Essa administração, embora passe por repartições policiais a partir da comunicação dos casos, é efetivamente concluída no seio das famílias, traçando um percurso semelhante ao da fotografia de Domingos, no caso com que abri este artigo. O retrato daquele desaparecido, afinal, foi entregue na delegacia pela comunicante do caso, mas por fim retornou a "um álbum de família".

Os principais instrumentos da administração dos casos pelas famílias são compromissos, obrigações e sentimentos relacionados ao controle de comportamentos, desejos e, ainda, da própria mobilidade dos desaparecidos, como sugerem os casos a seguir. Tais compromissos, obrigações e sentimentos funcionam como meios de administração de desaparecimentos porque, com efeito, estão registrados e arquivados em documentos policiais. São, afinal, compromissos, obrigações e sentimentos no papel, e carregam consigo a força social que isso implica e movimenta. O caso de Arlete é exemplar desse processo.

Dia 7 de janeiro de 2008: a empregada doméstica Regina saiu cedo para o trabalho, como de hábito. Voltou no horário também habitual, e encontrou sua filha Arlete, de 16 anos, assistindo à televisão. As duas jantaram juntas e, em seguida, Regina foi deitar, "deixando sua filha acordada, e sua filha falou que iria para a residência de sua colega Ana, e que lá iria dormir" (SDP/DH 131/08). No dia seguinte, trabalhou normalmente, mas quando voltou para casa não encontrou Arlete.

Nos quatro dias que se seguiram, a doméstica seguiu sua rotina, esperando ver Arlete ao voltar para casa. Isso não aconteceu. No dia 12 de janeiro foi então a uma DP e obteve um registro de desaparecimento da adolescente. Quase um mês depois, esteve novamente naquela repartição, agora para informar o contrário: que Arlete havia retornado. 
Em junho de 2008, o caso de Arlete, embora solucionado, foi equivocadamente encaminhado para o SDP. Antes de arquivá-lo, o policial que o recebeu achou por bem telefonar para Regina e encerrar o caso com o seguinte registro:

Por telefone a comunicante declarou que sua filha retornou para casa, após ficar alguns dias na companhia de colegas; disse ainda que desde então procura manter maior controle da menor, inclusive, a castigou com uma surra quando chegou em casa. Foi orientado que a mãe providenciasse carteira de identidade da menor (SDP/DH 131/08).

Desfecho semelhante teve o caso de Melissa, uma estudante de 14 anos que costumava passar um ou dois dias fora de casa sem dar notícias. Em abril de 2008, a adolescente passou três dias sem se comunicar com nenhum familiar, e sua mãe decidiu ir à DP. Na ocasião, foi feito registro de desaparecimento em nome de Melissa. Uma semana depois, a mãe da desaparecida retornou à repartição e relatou que a menina já estava em casa. A partir de seus relatos, o policial que a atendeu registrou:

Que segundo informações da comunicante, sua filha Melissa foi encontrada no bairro de Quintino na casa de uma amiga, sendo levada para casa para serem tomadas certas medidas com relação ao comportamento da mesma (SDP/DH 159/08).

Um tanto mais rico em detalhes e registros, por fim, é o caso de Cinira, uma universitária de 19 anos que deixou a casa em que vivia com a mãe e a irmã e retornou dez dias depois. Assim que voltou, a própria Cinira foi à DP onde seu desaparecimento fora registrado. Os registros da ida da desaparecida à repartição assemelham-se aos que constam do caso de Arlete e Melissa: firmam no papel compromissos com controle de comportamentos. No caso de Cinira, porém, são compromissos com o autocontrole e com o que seria uma boa condução de si, e não de outrem, como no caso de Arlete e Melissa. As falas da jovem ao policial que a atendeu restaram assim registradas:

[...] que na verdade não ocorreu nenhum crime relacionado a seu desaparecimento; que saiu da casa onde mora com sua mãe às 22:00 horas aproximadamente, não dando satisfação a ninguém, não fazendo nenhuma espécie de contato e reaparecendo 10 (dez) dias após o desaparecimento, dizendo que estava aborrecida com a vida, cansada e extremada; que a declarante está muito 
arrependida de não ter feito contato com a família, que quando sair para passear e demorar um pouco ligará para alguém de sua família, para comunicar onde e com quem está; a declarante disse [...] que durante o período em que ficou fora não sentiu vontade de falar com ninguém, atitude da qual se arrepende e muito (SDP/DH 020/08).

Essas confissões de culpa e arrependimento, assim como a surra registrada no caso de Arlete, os compromissos de controlar os próprios desejos, sentimentos e condutas, também no relato de Cinira, e ainda de punir o outro por seu comportamento, como vimos com a mãe de Melissa, certamente não foram relatados em repartições e registrados em documentos policiais gratuitamente. Sua efetividade como instrumentos de gestão dos casos decorre da força do próprio suporte material em que foram transcritos, embora, como vimos anteriormente, policiais encarem esses papéis como só procedimentos administrativos, pouco relevantes e pouco efetivos. Confirmam, enfim, que práticas burocráticas mundanas como apenas preencher papel são capazes de "alterar profundamente a forma como corpos são orientados, como vidas são vividas e como sujeitos são formados" (Ferguson \& Gupta 2002:984; tradução livre).

Compromissos, sentimentos e obrigações no papel são meios de gerir e mesmo solucionar desaparecimentos estabelecidos entre famílias e policiais, através da fronteira entre problemas de família e problemas de polícia delimitada pelos últimos. Consistem em modos de administrar casos que cruzam a linha delineada para apartar esses universos, sem, no entanto, ocultá-la ou desfazê-la. Compromissos, sentimentos e obrigações são recursos fundamentais da gestão de desaparecimentos, que tanto marcam e reproduzem a separação entre problemas de família e problemas de polícia, quanto evidenciam que os efeitos do que policiais "acabam fazendo" diante desse tipo de ocorrência não se confina ao espaço das delegacias.

Embora sejam registrados exclusivamente por policiais, compromissos, sentimentos e obrigações aparecem em casos de desaparecimento de pessoa como expedientes, meios de ação e afetos escolhidos, utilizados e experimentados em família. É revelador, nesse sentido, o primeiro registro do caso de Cinira, em que a jovem assegura "que não ocorreu nenhum crime em relação ao seu desaparecimento" (SDP/DH 020/08), o que eximiria a polícia de agir diante do caso. Não havendo crime, restaria à Cinira arrepender-se e assumir o compromisso, não fortuitamente firmado no papel, de contatar sua família sempre que se ausentar, mesmo que não deseje fazê-lo. Considerando as concepções dos policiais do SDP quanto a seu próprio trabalho, segundo as quais não havendo crime, resta-lhes apenas preencher papel, 
fica bastante claro que esse fazer policial não só registra, mas também enseja compromissos, obrigações e sentimentos com que as próprias famílias administram casos de desaparecimento. Os documentos preenchidos, manipulados e arquivados por policiais são, portanto, condutores de um processo de delegação de responsabilidades da polícia para as famílias, cuja efetividade deriva em larga medida da força social desses papéis.

\section{Considerações finais}

Durante o período em que realizei trabalho de campo no SDP, a Delegacia de Homicídios do Rio de Janeiro Centro/Capital, prestes a ser transformada em Divisão de Homicídios, ocupava integralmente o sétimo andar do edifício sede da Polícia Civil do Rio de Janeiro. O Setor consistia em uma pequena sala do andar, mobiliada com seis mesas de trabalho, quatro computadores, três aparelhos de telefone, alguns armários e muitos gaveteiros dispostos ao longo de três de suas quatro paredes. Só não havia gaveteiros na parede tomada, de um lado a outro, por janelas de vidro. Esses gaveteiros compunham o que chamei neste artigo de arquivos do SDP. Cada gaveta dos arquivos do Setor guardava, em pastas individuais, combinações variadas de formulários, ofícios, registros, fotografias e bilhetes que constituem casos de desaparecimento.

O argumento apresentado ao longo do presente texto é o de que esses papéis não são apenas rastros materiais de ocorrências policiais. Tampouco são mero cumprimento da função cartorial desempenhada por delegacias do Rio de Janeiro, embora sirvam, de fato, mais ao registro de práticas executadas por policiais, e menos ao acúmulo de insumos para sua investigação e solução (Miranda et al. 2010). Antes, registros policiais de casos de desaparecimento são parte constitutiva de dois processos principais através dos quais essas ocorrências são administradas: primeiro, a tomada de posição por parte dos policiais e, segundo, a delegação de responsabilidades às famílias de desaparecidos. Se documentos organizam, associam e relacionam pessoas (Hull 2012a:134), além de provocarem afetos das mais diversas ordens (Navaro-Yashin 2007), no escopo deste artigo busquei apresentar os processos, as relações e os afetos provocados e colocados em ação por registros policiais de casos de desaparecimento de pessoa.

A compreensão de tais processos explicita matizes e dimensões menos visíveis, mas não menos efetivos, do que Reis (1998) chama, em estudo sobre concepções de cidadania presentes no Brasil, de opressão burocrática. Exigências incontornáveis de registros e comprovações documentais até 
mesmo de que um sujeito está vivo, como é um dos casos tratados pela autora, seriam experimentados no Brasil como abusos, irracionalidades, excessos e evidências "do anonimato e da impessoalidade que são, no fundo, a tradução burocrática de dramas essencialmente humanos" (:249). A interpretação da autora assemelha-se à de DaMatta (2002), que sustenta que documentos são "sinais de um intolerável e brutal, porque impessoal e mecânico, controle político-burocrático" (:39). Em conjunto, ambos os autores colocam em relevo o caráter opressor da imprescindibilidade de papéis e documentos e apontam para experiências de frustração e humilhação por ela provocadas, associando-as invariavelmente à ideia de impessoalidade.

A análise de registros policiais de casos de desaparecimento traz à tona outras experiências e processos provocados pela imprescindibilidade de papéis e documentos em repartições públicas, revelando inclusive frustrações e tentativas de autoexoneração daqueles que têm a prerrogativa de produzir e arquivar registros, e não apenas compromissos, obrigações e sentimentos daqueles cujos desaparecimentos são objeto de registro. Revela, assim, que a chamada opressão burocrática incide também sobre os próprios burocratas que apenas preenchem papel e, como vimos no caso de Elói, executam um tipo de trabalho "que pouco conforma, apenas informa" (SDP/DH 394/05). Ademais, sugere que a própria ideia de opressão burocrática pode abarcar as numerosas e inescapáveis exigências de papéis nos mais variados contextos e situações, e também processos e afetos diversos, pouco ou nada impessoais, provocados por esses papéis.

Recebido em 29 de outubro de 2012

Aprovado em 28 de fevereiro de 2013

Letícia Carvalho de Mesquita Ferreira é pesquisadora bolsista do Centro de Pesquisa e Documentação de História Contemporânea do Brasil (CPDOC) da Fundação Getúlio Vargas (FGV). E-mail: <leticiacarvalho@gmail.com> 


\section{Notas}

* Uma versão inicial deste artigo foi apresentada no seminário "Processos de Estado, Violências e Desigualdades", realizado no Museu Nacional/UFRJ, em 24 e 25 de setembro de 2012. Agradeço a todos os presentes no evento pelas contribuições e questões levantadas.

${ }^{1}$ Todos os nomes próprios foram alterados para preservar as identidades dos sujeitos enredados nos desaparecimentos narrados ao longo do artigo.

${ }^{2}$ A expressão desaparecimento civil é utilizada (cf. Oliveira 2007) para marcar diferença em relação aos chamados desaparecimentos políticos, tipificados pelo Direito Internacional como desaparecimento forçado de pessoa. Definido no âmbito do Tribunal Penal Internacional em abril de 1998, e regulado pelo chamado Estatuto de Roma, por desaparecimento forçado de pessoas entende-se "a prisão, detenção ou sequestro de pessoas por um estado ou por organização política, ou com a autorização, apoio ou aquiescência destes, seguidos da negativa de informar sobre a privação de liberdade ou dar informação sobre a sorte ou o paradeiro dessas pessoas, com a intenção de deixá-las fora do amparo da lei por um período prolongado. Esse conceito foi mantido no Estatuto definitivo, enquanto crime contra a humanidade" (Jardim 2011:14).

${ }^{3}$ Faço uso do itálico ao longo do texto para destacar categorias e expressões correntes no SDP que se revelaram fundamentais para a compreensão da rotina do Setor. Propositalmente, entre as categorias e as expressões destacadas há tanto termos administrativos formalmente constitutivos do trabalho policial (p.ex., ocorrência, fato atípico e comunicante) quanto classificações e chaves interpretativas informais, mas acionadas com regularidade pelos policiais (p.ex., problema de polícia e problema de família). Essa reunião de categorias mais e menos formais responde, primeiro, à intenção de não produzir uma abordagem formalista do objeto aqui em foco e, segundo, ao entendimento de que práticas e representações informais vigentes em repartições burocráticas são menos indícios de uma incompletude da burocratização em certos países, e mais de que a burocracia é, na prática, uma questão de relações sociais (Herzfeld 1992:177), e não um universo de pura funcionalidade, impessoalidade e formalismo.

${ }^{4}$ Ao final do mês de dezembro de 2009, quando encerrei o trabalho de campo no SDP, a Delegacia de Homicídios passou por mudanças organizacionais e tornouse aquela hoje designada Divisão de Homicídios do Rio de Janeiro. O SDP segue funcionando como um setor da Divisão.

${ }^{5}$ Tendo por objetivo analisar os efeitos da produção, da circulação e do arquivamento de documentos sobre casos de desaparecimento de pessoa, não descreverei detidamente os tipos de documentos que compõem esses casos. Para uma descrição pormenorizada desses papéis, ver Ferreira (2011:72-112; 295-297). 
${ }^{6}$ Administrada pela Secretaria Nacional de Segurança Pública (Senasp), a Rede Infoseg "integra informações dos órgãos de Segurança Pública, Justiça e de Fiscalização em todo o país, provendo dados de pessoas com inquéritos, processos, mandados de prisão, além de dados de veículos, condutores e armas. A Rede Infoseg disponibiliza informações dos seguintes órgãos: Polícias Civis; Polícias Militares; Departamento Nacional de Trânsito; Exército Brasileiro; Superior Tribunal de Justiça e Justiça Federal; Departamento de Polícia Rodoviária Federal; Departamento de Polícia Federal; Secretaria da Receita Federal; Tribunais de Justiça Estaduais" (Senasp, s/d, p. 3). Só acessam a rede servidores de órgãos públicos autorizados pela Senasp para esse fim, mediante uso de senha pessoal. Todos os policiais do SDP têm senhas para utilizar a Rede Infoseg.

${ }^{7}$ Paes (2008) revela a definição policial de fato atípico ao descrever a rotina de atendimento a cidadãos por policiais de delegacias do Rio de Janeiro: "em primeiro lugar, os policiais realizam uma pequena entrevista com as pessoas para saber de que se trata o evento (classifica o fato como crime ou não), depois, [...] procuram impor uma definição legal ao crime, ver qual artigo do Código Penal pode ser atribuído ao fato - em caso de suspeita ou se estiver sendo sustada a existência de crime, são atribuídas algumas categorias administrativas, tais como remoção de cadáver, fato atípico ou auto de resistência" (Paes 2008:173).

${ }^{8}$ Sobre os caminhos e as decisões em torno da abertura ou não de inquéritos policiais no âmbito da Polícia Civil do Rio de Janeiro, e sobre os procedimentos inquisitoriais que marcam sua elaboração, ver Kant de Lima (1995) e Misse (2011). Sobre os padrões de registro e produção de inquéritos no mesmo contexto, ver Paes (2008) e Miranda et al. (2010).

${ }^{9}$ Eilbaum (2012) chama a atenção para o fato de que, embora em seu uso corrente nas delegacias do Rio de Janeiro a sigla VPI designe um tipo de conjunto documental, originalmente se refere à etapa da investigação policial que antecede e determina a instauração (ou não) de inquéritos policiais: "A sigla VPI provém do $\S 3^{\circ}$. do artigo $5^{\circ}$. do Código de Processo Penal Brasileiro. Refere-se a que, quando uma infração penal é comunicada à polícia, esta deve, uma vez verificada a procedência das informações, instaurar um inquérito policial. A partir do ato de verificar as informações, a polícia passou a criar uma peça administrativa burocrática própria, chamada VPI" (2012:414).

${ }^{10} \mathrm{Se}$, por um lado, o estatuto atribuído a VPIs e Sindicâncias é não só distinto, mas também inferior ao dos inquéritos policiais, a etnografia de Kant de Lima (1995:68-69) revela que tais procedimentos oferecem uma margem maior de autonomia a policiais do que os inquéritos, uma vez que seu arquivamento não depende de autorização por parte de um juiz ou promotor, e sim do arbítrio de um delegado.

${ }^{11}$ A dicotomia problemas de família x problemas de polícia encontra eco entre os (poucos) estudiosos dedicados ao fenômeno. De modo excludente, há interpretações que classificam o desaparecimento de pessoas como uma das faces da "violência 
urbana" (Espinheira 1999), enquanto outras o encaram como consequência direta da "violência intrafamiliar" (Oliveira \& Geraldes 1999) e de valores do patriarcalismo e seus impactos sobre relações de gênero e geração no interior de famílias brasileiras (Oliveira 2007).

${ }^{12}$ Em análise comparativa de padrões de atuação e operações policiais, Bayley (2006) reflete sobre a complexidade da tarefa de definir a natureza do trabalho da polícia e assegurar acesso permanente a ela. Para o autor, na prática de repartições e operações, a definição do que é o trabalho policial se faz constantemente, levando em conta "a descrição organizacional do que os policiais estão fazendo - patrulhando, investigando, controlando o tráfego, aconselhando e administrando" (:118), além da descrição do que usualmente fazem e, ainda, das múltiplas "situações com as quais a polícia se envolve: crimes em andamento, brigas domésticas, crianças perdidas, acidentes de automóvel, pessoas suspeitas, supostos arrombamentos, distúrbios públicos e mortes não naturais" (:119). A administração policial de casos de desaparecimento como os tratados no presente artigo revela, contudo, que em determinados contextos os próprios policiais definem o que é trabalho de polícia não a partir de, mas em contraposição a, parte do que estão fazendo, do que usualmente fazem e das situações que lhes são apresentadas.

${ }^{13}$ A demarcação de uma fronteira entre um universo de crimes e criminalidade em que é adequado haver intervenção por parte de poderes públicos e aquilo que seria de ordem familiar, demandando soluções privadas, aparece também na administração policial e judicial de casos de "violência doméstica" analisados por Muniz (1996), Soares (1999) e Enne, Vianna e Carrara (2002). Embora a questão fuja ao escopo deste artigo, vale apontar que o trabalho de Soares (1999), em especial, sugere que há muitas aproximações possíveis entre o SDP e as Delegacias de Atendimento à Mulher (DEAMs) do Rio de Janeiro, cujos funcionários "consideram-se diminuídos em suas carreiras quando são deslocados de outras delegacias para o atendimento de mulheres, pois acreditam que esse é apenas um trabalho de 'assistentes sociais' ou 'psicólogos'. Veem-se como meros burocratas e desconsideram a singularidade das histórias que lhes são contadas, diariamente, nos balcões" (:53).

${ }^{14}$ Araújo $(2008,2012)$ vem desenvolvendo pesquisas sobre a incidência do crime de desaparecimento forçado de pessoas no Brasil de hoje, a partir inicialmente de etnografia junto a um movimento que reúne familiares de vítimas de violência policial no Rio de Janeiro.

${ }^{15}$ Sobre processos de classificação de cadáveres não identificados no IML-RJ, ver Ferreira (2009). 


\section{Referências bibliográficas}

ABRAMS, Philip. 1988. "Notes on the difficulty of studying the state". Journal of Historical Sociology, I(I):58-89.

ARAÚJO, Fábio Alves. 2008. "Falta alguém na minha casa". In: Roberto Kant de Lima (org.), Antropologia e direitos humanos 5. Brasília: Booklink; ABA/ Fundação Ford. pp. 166-225. . 2012. Das consequências da "arte" macabra de fazer desaparecer corpos: sofrimento, violência e política entre familiares de vítimas de desaparecimento forçado. Tese de doutorado, Programa de Pós-Graduação em Sociologia e Antropologia da Universidade Federal do Rio de Janeiro.

BAYLEY, David H. 2006. Padrões de policiamento: uma análise comparativa internacional. (Coleção Polícia e Sociedade 1). São Paulo: Ford Foundation/NEV/Edusp.

BOLTANSKI, Luc. 1993. La souffrance à distance: morale humanitaire, médias et politique. Paris: Gallimard.

BOURDIEU, Pierre. 1996. "Espíritos de Estado: gênese e estrutura do campo burocrático". In: Razões práticas: sobre a teoria da ação. Campinas: Papirus. pp. 91-135.

CAPLAN, Jane \& TORPEY, John (eds.). 2001. Documenting individual identity: the development of state practices in the modern world. Princeton: Princeton University Press.

DAMATTA, Roberto. 2002. "A mão visível do Estado: notas sobre o significado cultural dos documentos na sociedade brasileira". Anuário Antropológico, 99:37-67.

EILBAUM, Lucía. 2012. "O bairro fala": conflitos, moralidades e justiça no conurbano bonaerense. São Paulo: Hucitec/ANPOCS.
ENNE, Ana Lúcia; VIANNA, Adriana R. B. \& CARRARA, Sérgio. 2002. "Entre o crime e a conciliação: a violência contra a mulher na justiça do Rio de Janeiro". Acervo: Revista do Arquivo Nacional, 15(1):39-58.

ESPINHEIRA, Gey. 1999. Desaparecimento e desaparecidos: um estudo de violência urbana. Salvador: CEFIJ.

FERGUSON, James \& GUPTA, Akhil. 2002. "Spatializing states: toward an ethnography of neoliberal governmentality". American Ethnologist, 29(4):981-1002

FERREIRA, Letícia Carvalho de Mesquita. 2009. Dos autos da cova rasa: a identificação de corpos não identificados no IML-RJ, 1942-1960. Rio de Janeiro: Finep/E-Papers.

2011. Uma etnografia para muitas ausências: o desaparecimento de pessoas como ocorrência policial e problema social. Tese de Doutorado, Programa de Pós-Graduação em Antropologia Social do Museu Nacional/UFRJ.

HERZFELD, Michael. 1992. The social production of indifference: exploring the symbolic roots of Western bureaucracy. Chicago: The University of Chicago Press.

HOAG, Colin. 2011. "Assembling partial perspectives: thoughts on the anthropology of bureaucracy". POLAR: Political and Legal Anthropology Review, 34(1):81-94.

HULL, Matthew. 2003. "The file: agency, authority, and the authography in an Islamabad bureaucracy". Language \& Communication, 23:287-314. . 2012a. "Documents and bureaucracy". Annual Review of Anthropology, 41:251-267. 
- 2012b. Government of paper: the materiality of bureaucracy in Urban Pakistan. Berkeley: University of California Press.

JARDIM, Tarciso Dal Maso. 2011. Brasil condenado a legislar pela Corte Interamericana de Direitos Humanos: da obrigação de tipificar o crime de desaparecimento forçado de pessoas. Brasília: Centro de Estudos da Consultoria do Senado/Textos para discussão, n. 83.

JEGANATHAN, Pradeep. 2004. "Checkpoint: anthropology, identity, and the State". In: Veena Das \& Deborah Poole (eds.), Anthropology in the margins of the state. Santa Fe: School of American Research Press. pp. 67-80.

KANT DE LIMA, Roberto. 1995. A polícia da cidade do Rio de Janeiro: seus dilemas e paradoxos. Rio de Janeiro: Editora Forense.

MIRANDA, Ana Paula Mendes de et al. 2010. "A reinvenção da 'cartorialização': análise do trabalho policial em registros de ocorrência e inquéritos policiais em 'Delegacias Legais' referentes a homicídios dolosos na cidade do Rio de Janeiro". Segurança, Justiça e Cidadania, 4:119-152.

MISSE, Michel. 2011. "O papel do inquérito policial no processo de incriminação no Brasil: algumas reflexões a partir de uma pesquisa". Revista Sociedade e Estado, 26(1):15-27.

MUNIZ, Jacqueline. 1996. "Os direitos dos outros e outros direitos: um estudo sobre a negociação de conflitos nas DEAMs/RJ". In: Luiz Eduardo Soares et al., Violência e política no Rio de Janeiro. Rio de Janeiro: ISER/ Relume Dumará. pp.125-164.

NAVARO-YASHIN, Yael. 2007. "Makebelieve papers, legal forms and the counterfeit: affective interactions between documents and people in
Britain and Cyprus". Anthropological Theory, 7:79-98.

OLIVEIRA, Dijaci David. 2007. Desaparecidos civis: conflitos familiares, institucionais e de segurança pública. Tese de Doutorado, Instituto de Ciências Sociais da Universidade de Brasília. - \& GERALDES, Elen Cristina. 1999. Cadê você. Brasília: Movimento Nacional de Direitos Humanos.

PAES, Vivian Ferreira. 2008. "'Quem domina a regra do jogo': sobre a reforma da polícia e os registros policiais". In: Michel Misse (org.), Acusados \& acusadores: estudos sobre ofensas, acusações e incriminações. Rio de Janeiro: Faperj/Editora Revan. pp. 165-186.

PEIRANO, Mariza. 1986. "Sem lenço, sem documento". Sociedade e Estado, 1:49-63.

- 2006a. "De que serve um documento?". In: Moacir Palmeira \& César Barreira (orgs.), Política no Brasil: visões de antropólogos. Rio de Janeiro: Relume Dumará, NuAP/UFRJ. pp. 13-37.

— 2006b. "A lógica múltipla dos documentos". In: A teoria vivida e outros ensaios de antropologia. Rio de Janeiro: Jorge Zahar Editor. pp. 135-153.

- 2009. "O paradoxo dos documentos de identidade: relato de uma experiência nos Estados Unidos". Horizontes Antropológicos, 32:53-80.

REIS, Elisa Pereira. 1998. "Opressão burocrática: o ponto de vista do cidadão". In: Processos e escolhas. Rio de Janeiro: Contra Capa Livraria. pp. 239-269.

RIO DE JANEIRO. 1991. Secretaria de Estado de Segurança Pública. Resolução SEPC 513 de 16 de dezembro de 1991. Rio de Janeiro: Secretaria de Estado de Segurança Pública. 
RILES, Annelise. 2006. "Introduction: in response". In: (ed.), Documents: artifacts of modern knowledge. Ann Arbor: The University of Michigan Press. pp. 1-38.

SANTOS, Wanderley Guilherme dos. 1979. Cidadania e justiça: a política social na ordem brasileira. Rio de Janeiro: Editora Campus.

SENASP. Rede Infoseg. Disponível em: http://www.infoseg.gov.br/infoseg/ arquivos/infoseg.pdf. Acesso em: 23/11/2008.

SOARES, Bárbara Musumeci. 1999. Mulheres invisíveis: violência conjugal e novas políticas de segurança. Rio de Janeiro: Civilização Brasileira.

SOUZA LIMA, Antonio Carlos de. 2002. "Sobre gestar e gerir a desigualdade: pontos de investigação e diálogo". In: _. (org.), Gestar e gerir: estudos para uma antropologia da administração pública no Brasil. Rio de Janeiro: Relume Dumará/NuAP/UFRJ. pp. 11-22.

WEBER, Max. 1963. "Burocracia". In: Ensaios de sociologia. Rio de Janeiro: Zahar Editores. pp. 229-282.

\section{Documentos}

Setor de Descoberta de Paradeiros da Delegacia de Homicídios do Rio de Janeiro Centro/Capital (SDP/DH). 


\section{Resumo}

O artigo analisa registros policiais de casos de desaparecimento de pessoa produzidos e arquivados em delegacias de Polícia Civil do Rio de Janeiro entre 2005 e 2009. Argumenta-se que esses papéis não são apenas rastros materiais das ocorrências neles registradas, e sim forças motrizes de dois processos principais através dos quais desaparecimentos de pessoa são administrados. O primeiro é a tomada de posição por parte de policiais diante dos casos, a partir do par de opostos "problemas de família" e "problemas de polícia". O segundo, que ganha sentido no marco do primeiro, é a delegação de responsabilidades às famílias dos desaparecidos, que acabam por gerir e mesmo solucionar os casos por meio de compromissos, obrigações e afetos.

Palavras-chave Desaparecimento de pessoas, Registros policiais, Documentos.

\section{Abstract}

The present article analyses police records for missing persons that were registered and filed in police stations of Rio de Janeiro from 2005 to 2009. It argues that these documents are not only material traces of the facts therein registered, but also the driving forces for two main processes through which missing persons cases are managed. The first process is a statement of position towards the cases constructed by police officers out of the opposing pair "a family problem" and "a police problem". The second process, which makes sense within the framework of the first, is the delegation of responsibilities to the missing persons families, who ultimately manage and even solve the cases by means of commitments, obligations and affection.

Key words Missing persons, Police records, Documents. 